\title{
MIKHAIL BAKHTIN E KARL MARX: CONSCIÊNCIA E LINGUAGEM
}

\author{
Francisco Brandão Aguiar ${ }^{1}$ \\ Eduardo Ferreira Chagas ${ }^{2}$
}

\begin{abstract}
Resumo:
Neste trabalho buscaremos analisar a relação entre os conceitos de consciência e linguagem a partir de Mikhail Bakhtin e Karl Marx. Neste sentido, no que se refere a Mikhail Bakhtin teremos como escopo principal a obra, Marxismo e Filosofia da Linguagem: problemas fundamentais do método sociológico na ciência da linguagem. No tocante a Karl Marx, percorreremos obras como, A Ideologia Alemã, O capital e Contribuição a Crítica da Economia política. Nossa análise gira sempre em torno da construção dos conceitos de consciência e linguagem em Bakhtin, procurando articulá-los com os pontos de vista desenvolvidos na teoria marxista. Acreditamos que exista uma determinada viabilidade para tal conexão entre os pensadores, uma vez que, a construção da Filosofia da Linguagem de Bakhtin sofre influencia direta da Filosofia Marxista. Nossa pesquisa caracteriza-se como bibliográfica, indireta, qualitativa e se desenvolve por meio da interlocução crítico-discursiva. Concluímos que, a linguagem assim como a consciência tem em comum o fato de necessitarem construir suas bases no contexto histórico social e real. Marx e Bakhtin buscam rechaçar qualquer compreensão idealista referente a esses conceitos. Mais que isso, os autores estão denunciando as posturas metodológicas que introduzem um caráter irreal e atemporal aos conceitos determinantes da sociedade.
\end{abstract}

Palavras-chave: Mikhail Bakhtin. Karl Marx. Consciência. Linguagem.

\section{MIKHAIL BAKHTIN AND KARL MARX: CONSCIOUSNESS AND LANGUAGE}

\begin{abstract}
:
In this work we will seek to analyze the relationship between the concepts of consciousness and language starting Mikhail Bakhtin and Karl Marx. In this sense, in relation to Mikhail Bakhtin we will have as main book, Marxism and Philosophy of Language: fundamental problems of the sociological method in the science of language. In relation to Karl Marx, we go through books like, The German Ideology, The Capital and A Contribution to the Critique of Political Economy. Our analysis is about the construction of the concepts of language and
\end{abstract}

1 Doutorando em Educação pela Universidade Federal do Ceará - UFC. Mestre em Filosofia pela Universidade Estadual do Ceará - UECE. Especialista em Gestão Escolar pelo Instituto Superior de Educação Elvira Dayrell - ISEED. Especialista em Docência no Ensino Superior pela Universidade Candido Mendes - UCAM. Graduado em Pedagogia pelo Instituto Superior de Educação Elvira Dayrell - ISEED. Graduado em Filosofia pela Universidade Estadual Vale do Acaraú - UVA. E-mail: francisco_ba89@ hotmail.com.

2 Graduado em Filosofia pela Universidade Estadual do Ceará (UECE, 1989), Mestrado em Filosofia pela Faculdade de Filosofia e Ciências Humanas (FAFICH) da Universidade Federal de Minas Gerais (UFMG, 1993), Doutorado em Filosofia pela Universität von Kassel (KASSEL, ALEMANHA, 2002) e Pós-Doutorado em Filosofia pela Universität Münster (Alemanha) (2018-2019). É Professor efetivo (Associado) do Curso de Filosofia e do Programa de Pós-Graduação em Filosofia da Universidade Federal do Ceará (UFC) e Professor Colaborador do Programa de Pós-Graduação em Educação Brasileira da FACED - UFC. Coordenador do Grupo de Estudos Marxistas - GEM -, vinculado ao Eixo Marxismo, Teoria Crítica e Filosofia da Educação, e ao Programa de Pós-Graduação em Educação Brasileira da FACED- UFC. Atualmente, é Pesquisador Bolsista de Produtividade do CNPQ, é membro da Internationale Gesellschaft der Feuerbach-Forscher (Sociedade Internacional Feuerbach) e dedica suas pesquisas ao estudo da Filosofia Política, da Filosofia de Hegel, do Idealismo Alemão e de seus críticos Feuerbach, Marx, Adorno e Habermas. E-mail: ef.chagas@uol.com.br. Academia.edu: https://ufc.academia.edu/EduardoFChagas. Homepage: www.efchagas.wordpress.com Editor da Revista Dialectus (http://periodicos.ufc.br/dialectus) (http://www.revistadialectus.ufc.br/index.php/RevistaDialectus/about/editorialPolicies\#sectionPolicies). C.V (Lattes): $\quad$ http://lattes.cnpq.br/2479899457642563.

(http://buscatextual. cnpq.br/buscatextual/visualizacv.do?id=K4794196Y0). ORCID: https://orcid.org/0000-0003-1957-6117. Canal Eduardo Chagas no YouTube https://www.youtube.com/channel/UCx4G8MH51hFuGYvoBguhHbQ. 
consciousness in Bakhtin, articulating these concepts with the Marxist theory. We believe that there is a viability for a connection between thinkers, because the construction of Bakhtin's Philosophy of Language is influenced by Marx. This research is characterized as bibliographical, indirect, qualitative and occurs through critical-discursive dialogue. We concluded that, language as well as consciousness have in common the fact that they need to build their bases in the social and real historical context. Marx and Bakhtin seek to reject any idealistic understanding of these concepts. More than that, the authors are denouncing the methodological stances that introduce an unreal and timeless character to the determinant concepts of society.

Keywords: Mikhail Bakhtin. Karl Marx. Consciousness. Language.

\section{Introdução}

Neste trabalho temos como propósito mostrar a relação entre os conceitos de consciência e linguagem a partir de Mikhail Bakhtin e Karl Marx. Nesse sentido, quanto a Bakhtin, nosso escopo principal é a obra Marxismo e Filosofia da Linguagem: problemas fundamentais do método sociológico na ciência da linguagem. No que se refere a Marx, perpassaremos por obras como: A ideologia alemã, O capital e Contribuição à crítica da economia política.

Nossa análise gira sempre em torno da construção dos conceitos de linguagem e consciência em Bakhtin, procurando articulá-los com os pontos de vista desenvolvidos na teoria marxista. Acreditamos que exista uma determinada viabilidade para tal conexão entre os pensadores, uma vez que, a construção da Filosofia da Linguagem de Bakhtin está baseada na concepção dialógica da natureza humana, onde ele busca manter uma determinada proximidade com a teoria marxista.

No primeiro momento de nosso trabalho, buscaremos mostrar a necessidade de uma abordagem marxista acerca da Filosofia da Linguagem. Em seguida, traremos o problema da consciência no pensamento bakhtiniano e por último, trataremos da relação entre os conceitos de consciência e linguagem a partir de Mikhail Bakhtin e Karl Marx.

Essa pesquisa caracteriza-se como bibliográfica, indireta, qualitativa e se desenvolve por meio da interlocução crítico-discursiva, sendo assim, fundamentada em Karl Marx, Mikhail Bakhtin e outros autores (comentadores) que tratam de questões relativas à nossa temática.

Mikhail Bakhtin e a necessidade de uma abordagem marxista acerca da Filosofia da Linguagem

\begin{tabular}{|c|c|c|c|c|}
\hline Rovista Dialectus & Ano 9 & n. 19 & Agosto - Dezembro 2020 & p. $278-288$ \\
\hline
\end{tabular}


O teórico, pensador e filósofo Mikhail Mikhailovich Bakhtin (1895-1975) foi uma das figuras mais importantes para a história e o desenvolvimento de estudos acerca da linguagem humana. Suas pesquisas, que norteiam até hoje estudos e teorias pelo mundo, abrangem temas relacionados à História, Filosofia, Antropologia, Psicologia, Sociolinguística, Análise do Discurso e Semiótica. Sendo que, sua maior contribuição intelectual foi o legado dos estudos da linguagem, que é considerado por muitos estudiosos como uma visão translinguística. De acordo com Bakhtin, a língua não se encaixa em um sistema isolado e qualquer análise linguística deve tratar também de outros fatores, como a relação do emissor com o receptor, o contexto social, histórico, cultural e ideológico. (BAKHTIN, 2006).

Bakhtin irá buscar um entendimento acerca das correntes de pensamento que percorreram o século $\mathrm{XX}$, evitando sempre o dogmatismo e o relativismo que permeavam as posturas dessa época. Assim, na obra Problemas da Poética em Dostoiévski, o autor afirma que o dogmatismo e o relativismo excluem-se igualmente em qualquer discussão. Portanto, o primeiro passo da teoria Bakhtiniana é tratar de uma análise da sociedade a partir dos problemas da linguagem, numa perspectiva histórico-dialética. Esse pensador antecipa bastante às orientações da linguística moderna, principalmente, em relação aos conceitos de consciência e linguagem.

Na obra Marxismo e Filosofia da Linguagem ${ }^{3}$, Bakhtin irá afirmar que o espírito filosófico do marxismo ainda não penetrou nos domínios da linguagem. Para ele, como veremos mais adiante, as correntes teórico-metodológicas que tratam desse tema compreendem a linguagem não-dialeticamente, mas como algo intangível e imutável. Ele acredita que, "não existe atualmente uma única análise marxista no domínio da linguagem feita por grandes pensadores. Nem sequer há nos trabalhos marxistas alguma formulação, a respeito desta, que seja um pouco precisa e desenvolvida.” (BAKHTIN, 2006, p. 24).

É esse o propósito para o qual o autor direciona as primeiras linhas da obra (citada imediatamente no parágrafo anterior), isto é, Bakhtin expõe a necessidade de uma abordagem marxista da Filosofia da Linguagem e irá tratar das questões da linguagem colocando sob o signo da dialética o efeito das estruturas sociais. $\mathrm{O}$ autor traz, em primeiro lugar, a questão dos

\footnotetext{
${ }^{3}$ De acordo com Bubnova (2009), difundiu-se no ocidente, a partir das afirmações do semiólogo Viacheslav Ivanovich Ivanov, que a autoria de Marxismo e Filosofia da Linguagem não pertencia a Volóchinov e sim a seu mestre Bakhtin. As traduções que foram surgindo posteriores aos estudos de Ivanov variam, atribuindo-se a autoria ora a um, ora a outro e, por muitas vezes, aos dois. Ao que se sabe, Bakhtin recusava-se a fazer concessões a fraseologia da época e a certos dogmas imposto aos autores.
}

\begin{tabular}{|l|c|c|c|c|}
\hline Renista Dialectus & Ano 9 & n. 19 & Agosto-Dezembro 2020 & p. 278 - 288 \\
\hline
\end{tabular}


dados reais da linguística, da natureza real dos fatos da língua. A língua é um fato social, cuja existência se funda nas necessidades da comunicação.

Mikhail Bakhtin procura mostrar a importância da Filosofia da Linguagem para as Ciências Sociais, ele acredita que os problemas da linguagem adquiriram, recentemente, uma atualidade e uma importância excepcional para o marxismo. O pensador argumenta que, na maioria dos setores mais importantes do seu desenvolvimento científico, o marxismo vai diretamente de encontro a esses problemas e não pode avançar de maneira eficaz sem submetêlos a um exame específico. (BAKHTIN, 2006).

Uma das primeiras abordagens que Bakhtin traz em seu contexto filosófico remete ao problema da consciência. Ele acredita que as posturas que tratam de uma análise teórica da consciência, até então, não conseguiram concebê-la de forma satisfatória, fato este que acabou gerando consequências drásticas para uma análise da linguagem. Veremos, em seguida, como o autor trata dessa questão.

\section{O problema da consciência em Mikhail Bakhtin}

Para Bakhtin, o estudo da consciência gerou um problema que criou dificuldades e confusões no campo da Psicologia e da Linguagem. Ele defende que, de maneira geral, a consciência tornou-se asylum ignorantiae de todo edifício filosófico. Foi transformada em depósito de todos os problemas não resolvidos, de todos os resíduos objetivamente irredutíveis. Ao invés de buscar uma definição objetiva da consciência, esta foi usada para tornar subjetiva e fluídas certas noções até então sólidas e objetivas.

Bakhtin defende que existe uma tarefa essencial e urgente do marxismo em relação ao sujeito. Essa tarefa gira em torno da construção de uma psicologia verdadeiramente objetiva. Assim, os fundamentos dessa nova psicologia objetiva não devem ser fisiológicos, nem biológicos, mas sociológicos. Bakhtin pontua que "de fato, o marxismo encontra-se frente a uma árdua tarefa: a procura de uma abordagem objetiva, porém refinada e flexível do psiquismo subjetivo consciente do homem, que em geral é analisado pelos métodos de introspecção.” (BAKHTIN, 2006, p.47).

Para Bakhtin, a Biologia e a Fisiologia não oferecem condições de resolver o problema da consciência no sujeito. Isso porque ele acredita que a consciência constitui um fato sócio-ideológico, não acessível a métodos empregados pela fisiologia ou pelas ciências naturais. Tal como ocorre nessas ciências, ele acredita que é impossível reduzir o

\begin{tabular}{|l|l|l|l|l|}
\hline Gevista Dialectus & Ano 9 & n. 19 & Agosto-Dezembro 2020 & p. 278-288 \\
\hline
\end{tabular}


funcionamento da consciência a alguns processos que se desenvolvem no interior do campo fechado de um organismo vivo. Assim, os processos que no essencial determinam o conteúdo do psiquismo desenvolvem-se não no organismo, mas fora dele, ainda que o organismo individual participe desses processos.

O psiquismo subjetivo do sujeito não constitui um objeto de análise para as Ciências Naturais, pois não se trata de uma coisa ou de um processo natural. O psiquismo subjetivo é o objeto de uma análise ideológica, de onde se depreende uma interpretação sócio-ideológica. O fenômeno psíquico, uma vez compreendido e interpretado, é explicável exclusivamente por fatores sociais que determinam a vida concreta de um dado indivíduo. (BAKHTIN, 2006, 2017).

A que tipo de realidade pertence ao psiquismo subjetivo do sujeito então?

Bakhtin é enfático ao afirma que realidade do psiquismo interior do sujeito é a do signo. Sem material semiótico não se pode falar em psiquismo. Pode-se falar somente em processos fisiológicos ou em processos do sistema nervoso. Em relação à realidade exterior ao organismo, essa pode até caracterizar-se como um campo onde o psiquismo reage, mas essa reação ocorre sempre por mediação do signo, de uma maneira ou de outra. Cito Bakhtin

\begin{abstract}
Por natureza, o psiquismo subjetivo localiza-se no limite do organismo e do mundo exterior, vamos dizer, na fronteira dessas duas esferas da realidade. É nessa região limítrofe que se dá o encontro entre o organismo e o mundo exterior, mas este encontro não é físico: o organismo e o mundo encontram-se no signo. A atividade psíquica constitui a expressão semiótica do contato entre o organismo e o meio exterior. Eis porque o psiquismo interior não deve ser analisado como uma coisa; ele não pode ser compreendido e analisado senão como um signo (BAKHTIN, 2006, p.48).
\end{abstract}

Na obra O freudismo: um esboço crítico, Bakhtin (2017) argumenta que esse conteúdo da nossa consciência e de todo o psiquismo em seu conjunto, como aquelas enunciações isoladas através das quais esse conteúdo se revela no exterior, são determinadas sob todos os aspectos por fatores socioeconômicos. Nunca chegaremos às raízes verdadeiras e à essência de uma enunciação singular se as procurarmos apenas nos limites de um organismo individual, mesmo quando tal enunciação concernir aos aspectos pessoais e íntimos da vida do homem.

Compreender um signo consiste em aproximar o signo apreendido de outros já conhecidos; em outros termos, a compreensão é uma resposta a um signo por meio de signos. Essa cadeia de criatividade e de compreensão ideológica (uma vez que a língua se caracteriza como realidade material específica da criação ideológica) desloca-se de signo em signo, para

\begin{tabular}{|l|l|l|l|l|}
\hline Q Rovista Dialectus & Ano 9 & n. 19 & Agosto-Dezembro 2020 & p. 278-288 \\
\hline
\end{tabular}


um novo signo e é única e contínua. Em nenhum ponto a cadeia se quebra, em nenhum ponto ela penetra a existência interior, de natureza não material e não corporificada em signos. (BAKHTIN, 2006).

Essa cadeia ideológica estende-se de consciência individual a consciências individuais, ligando umas às outras. Os signos só emergem, decididamente, do processo de interação entre uma consciência individual e uma outra. E a própria consciência individual está repleta de signos. A consciência só se torna consciência quando se impregna de conteúdo ideológico (semiótico) e, consequentemente, somente no processo de interação social.

Apesar de suas profundas diferenças metodológicas, a filosofia idealista e o psicologismo, em matéria de cultura, cometem o mesmo erro fundamental. Essas posturas situam a ideologia na consciência transformando, desta forma, o estudo das ideologias em estudo da consciência e de suas leis: pouco importa que isso seja feito em termos transcendentais ou em termos empírico-psicológicos. Esse erro não só é responsável por uma confusão metodológica acerca da inter-relação entre domínios diferentes do conhecimento, como também por uma distorção radical da realidade estudada. A criação ideológica, ato material e social, é introduzida à força no quadro da consciência individual. Esta, por sua vez, é privada de qualquer suporte na realidade. (BAKHTIN, 2006).

\section{Bakhtin e Marx: consciência e linguagem}

Bakhtin, assim como Marx, acredita que os teóricos, ideólogos e os intelectuais, em sua maioria, não estão diretamente vinculados à produção material das condições de existência da vida humana. Existe, portanto, uma fissura entre a realidade material e o conhecimento teórico que tenta abarcar essa realidade. Para Bakhtin a realidade, que está diretamente ligada à construção contínua de ideologias, é tratada como um problema da consciência e não como um problema da realidade concreta dos homens. Marx, no sentido da afirmação anterior, na Ideologia Alemã , irá fazer duras críticas a Max Stirner e Bruno Bauer por defenderem uma autonomia da História em relação aos homens históricos reais. De acordo com Marx, para esses pensadores as ideias é que condicionariam as situações materiais dos homens em cada momento histórico. Portanto, a consciência é que produziria as condições materiais dos homens. (MARX, 2001).

Marx irá argumentar que, para os jovens hegelianos, as representações, ideias, conceitos, enfim, os produtos da consciência aos quais eles próprios deram autonomia, eram

\begin{tabular}{|l|l|l|l|l|}
\hline Gevista Dialectus & Ano 9 & n. 19 & Agosto-Dezembro 2020 & p. 278-288 \\
\hline
\end{tabular}


considerados como verdadeiros grilhões da humanidade. Assim, os jovens hegelianos lutavam unicamente contra essas ilusões da consciência. Citamos Marx,

\begin{abstract}
As relações dos homens, todos os seus atos e gestos, suas cadeias e seus limites são postos como produtos da sua própria consciência, coerentes consigo próprios [...]. Nenhum desses filósofos teve a ideia de se perguntar qual era a ligação entre a filosofia alemã e a realidade alemã, a ligação entre a crítica e o seu próprio meio material. (MARX; ENGERLS, 2001, pp.10-11).
\end{abstract}

Esses filósofos só oferecem a história das representações, desligada dos fatos e dos desenvolvimentos práticos que constituem sua base. Esses pensadores só oferecem a história com a finalidade de representar a época em foco como uma primeira etapa imperfeita, como um anúncio, ainda limitado, da verdadeira época histórica. (MARX; ENGELS, 2001).

Para Marx, Feuerbach leva sobre os materialistas "puros" a grande vantagem de perceber que o homem é também um "objeto sensível”, entretanto, ele considera o homem unicamente como objeto sensível e não como "atividade sensível”, ou seja, ele se contenta com a teoria e não considera os homens em seu determinado contexto social, em suas reais condições de vida.

De acordo com Marx, Feuerbach fica numa abstração: “o homem” e só chega a reconhecer o homem real, individual, em carne e osso, no sentimento. Em outras palavras, não conhece outras relações humanas (do homem para com o homem) que não seja o amor e amizade, ainda assim idealizados. Ele não critica as atuais condições de vida. Nunca chega, portanto, a considerar o mundo sensível como à soma da atividade viva e física dos indivíduos que compõem esse mundo. E quando Feuerbach vê, em vez de homens saudáveis, um bando de famintos, esgotados e tuberculosos, é obrigado a apelar para a concepção superior das coisas e para a igualização ideal no gênero. Logo, recai no idealismo. (MARX; ENGELS, 2001).

Marx e Bakhtin estão denunciando o caráter abstrato das teorias filosóficas, sociais e linguísticas. Esses pensadores irão defender que a ideologia da classe dominante nasceria dessa fissura da práxis vigente e, por isso, descola-se da realidade material concreta. Seus produtores (os teóricos, ideólogos, intelectuais etc.) não estão diretamente vinculados à produção material das condições de existência. De acordo com Marx, a ideologia propagada pela sociedade do capital é algo produzido pelo poder dominante e expressa em ideias os interesses desse mesmo poder, "apresentando seu próprio interesse como interesse geral de todos os membros da sociedade [...], a imprimir a suas ideias a forma da universalidade, a

\begin{tabular}{|l|l|l|l|l|}
\hline Gevista Dialectus & Ano 9 & n. 19 & Agosto - Dezembro 2020 & p. 278-288 \\
\hline
\end{tabular}


apresentar essas ideias como as únicas racionais e validas universalmente." (MARX; ENGELS, 2007, p.72).

Bakhtin, seguindo a mesma linha de raciocínio do parágrafo anterior, diz que "a classe dominante tende a conferir ao signo ideológico um caráter intangível e acima das diferenças de classe, a fim de abafar ou ocultar a luta dos índices sociais de valor que aí se travam, a fim de tornar o signo monovalente.” (BAKHTIN, 2006, p. 46). Ou, para usarmos uma citação já mencionada da Ideologia alemã, “a classe dominante busca apresentar o seu próprio interesse como interesse geral de todos os membros da sociedade." (MARX; ENGELS, 2007, p.72). Marcondes (2005) acrescenta que, ao falarmos de ideologia estamos falando, portanto, de um discurso ideológico. Isso significa entendermos a crítica da ideologia como parte de uma concepção pragmática de linguagem.

Marx não trata, especificamente, sobre um conceito linguagem em suas minúcias, no entanto, na Ideologia Alemã ele traz uma determinada afirmação sobre tal conceito. Neste viés, a linguagem é mostrada como a consciência prática, podemos deduzir então que isso representa uma forma de inserção da consciência na realidade dos fatos (em concordância com Bakhtin). De Acordo com Marx,

\begin{abstract}
A linguagem é tão velha quanto à consciência: a linguagem é a consciência prática, a consciência real, que existe também para os outros homens e que, portanto, começa a existir também para mim mesmo; e a linguagem nasce, assim como a consciência, da necessidade, da carência de intercâmbio com os demais homens. [...] A consciência é, portanto, já de antemão, um produto social, e o seguira sendo enquanto existirem seres humanos. (MARX; ENGELS, 2007, p. 53).
\end{abstract}

Portanto, se a linguagem é tão velha quanto à consciência e a linguagem é a consciência prática, as bases matérias da consciência são as mesmas da linguagem, a saber: o homem, sua relação com o trabalho e a constituição de uma sociedade sobre determinada divisão do trabalho.

Bakhtin (2006) dirá que, a própria consciência só pode surgir e se afirmar como realidade, mediante a encarnação material em um signo. O pensador afirmará ainda que, (como dito antes) os signos só emergem do processo de interação entre uma consciência individual e uma outra. Bakhtin está denunciando a impossibilidade da fala como algo absolutamente individual, não existe uma atividade mental sem expressão semiótica. "Não é a atividade mental que organiza a expressão, mas, ao contrário, é a expressão que organiza a atividade mental, que a modela e determina sua orientação.” (BAKHTIN, 2006, p. 114).

\begin{tabular}{|c|c|c|c|c|}
\hline Q Rovista Dialectus & Ano 9 & ก. 19 & Agosto - Dezembro 2020 & p. $278-288$ \\
\hline
\end{tabular}


Cada enunciação, cada ato de criação individual é único e não reiterável, mas em cada enunciação encontram-se elementos idênticos aos de outras enunciações no seio de um determinado grupo de locutores. São justamente estes traços idênticos que são assim normativos para todas as enunciações - traços fonéticos, gramaticais e lexicais -, que garantem a unicidade de uma dada língua e sua compreensão por todos os locutores de uma mesma comunidade. (BAKHTIN; 2006, p. 77).

A enunciação monológica já é uma abstração, embora seja uma abstração do tipo natural. Toda enunciação monológica, inclusive uma inscrição num monumento, constitui um elemento inalienável da comunicação verbal. (BAKHTIN, 2006). Entender o sistema linguístico como algo autônomo, desvinculado dos homens reais em condições históricas reais, ignorando as enunciações e atos de fala por serem absolutamente individuais, caracteriza esse sistema como idealizado, pois o considera como descolado dos homens que o produzem.

Por outro lado, assumir a vida psíquica individual do falante como o núcleo gerador da linguagem, ignorando que ela é gerada, antes de tudo, pela interação ou intercâmbio entre indivíduos reais em condições históricas reais, acaba por postular um indivíduo idealizado, pois ignora coerções de ordem social presentes na própria língua. (VIANNA, 2010).

Portanto, se é da natureza da palavra dirigir-se de alguém para alguém, cabe aos estudiosos da linguagem analisar esse processo, cuja manifestação real se dá por meio do enunciado concreto. Bakhtin argumenta que a verdadeira substância da língua não é constituída por um sistema abstrato de formas linguísticas, tão pouco pela enunciação monológica isolada, e muito menos ainda pelo ato psicológico de sua produção, mas pelo fenômeno social da interação verbal, realizada por meio da enunciação ou das enunciações. "A interação verbal constitui assim a realidade fundamental da língua.” (BAKHTIN, 2006, p. 127).

Marx (1983), por sua vez, critica a posição que defende os conceitos como algo que determina as condições materiais da existência (como pensam os filósofos especulativos). Neste sentido, o conceito de História para Marx (1983), abordado na Contribuição à Crítica da Economia Política, não é um conceito desenvolvido do espírito abstrato até a sua efetivação, mas sim, uma história real da luta de classes, do intenso conflito entre a burguesia e o proletariado. Em Marx, as bases fundamentais da construção da história dos homens são de origem social. (2003, p.1). Nas Teses sobre Feuerbach, Marx resaltará que "Toda vida social é essencialmente prática. Todos os mistérios que conduzem ao misticismo encontram sua solução racional na práxis humana e na compreensão dessa práxis".

\begin{tabular}{|c|c|c|c|c|}
\hline Rovista Dialectus & Ano 9 & n. 19 & Agosto - Dezembro 2020 & p. $278-288$ \\
\hline
\end{tabular}


Marx está assumindo, na Introdução da Contribuição à Critica da Economia Política, a mesma postura que assume na Ideologia Alemã e que Bakhtin incorpora em Marxismo e Filosofia da Linguagem, isto é: as bases fundamentais de construção da história dos homens, bem como as bases da linguagem e da consciência, têm que ser necessariamente de origem social.

\section{Considerações finais}

Com esta pesquisa buscamos mostrar uma aproximação entre os conceitos de consciência e linguagem, a partir de Karl Marx e Mikhail Bakhtin. Observamos que tal aproximação torna-se possível pelo fato de que, a Filosofia da Linguagem de Bakhtin está baseada na concepção dialógica da natureza humana, onde o foco está nas contradições e conflitos da práxis social, identificando-se desta maneira com a concepção marxista de mundo.

Concluímos que, tanto Bakhtin quanto Marx, no tocante aos conceitos de consciência e linguagem, têm em comum o confronto no que se refere a uma compreensão idealista e autônoma dessas categorias. Marx, ao criticar os jovens hegelianos, diz que as representações, ideias e conceitos, enfim, os produtos da consciência, aos quais eles próprios deram autonomia, eram considerados como verdadeiros grilhões da humanidade, e assim, esses pensadores lutavam unicamente contra essas ilusões. Ao referir-se à linguagem, Marx afirma que ela é a consciência prática, logo, as bases matérias da consciência são as mesmas da linguagem, a saber: o homem, sua relação com seu trabalho e a constituição de uma sociedade sobre determinada divisão do trabalho.

Bakhtin, em concordância com a perspectiva marxista, mostra que a estrutura mental do sujeito e da sua enunciação é de origem social, bem como os processos interativos que constituem toda a cadeia verbal social. Assim, o autor defende que os signos só se apresentam, decididamente, do processo de interação entre uma consciência individual e uma outra. A própria consciência individual está repleta de signos e ela só se torna consciência no processo de interação.

Percebemos ainda que, a consciência e a linguagem necessitam construir suas bases no contexto histórico da realidade concreta. Marx e Bakhtin rechaçam qualquer compreensão idealista refrente a esses conceitos. Mais que isso, os autores estão denunciando as posturas metodológicas que introduzem um caráter irreal e atemporal aos conceitos determinantes da sociedade.

\begin{tabular}{|l|l|l|l|l|}
\hline Qevista Dialectus & Ano 9 & n. 19 & Agosto - Dezembro 2020 & p. $278-288$ \\
\hline
\end{tabular}




\section{Referências}

BAKHTIN, Mikhail Mikhailovitch. O freudismo: um esboço crítico. Tradução de Paulo Bezerra. São Paulo: Perspectiva, 2017.

Problemas da poética de Dostoiévski. Trad. Paulo Bezerra. 5. ed. Rio de Janeiro: Forense Universitária, 2010.

; VOLÓCHINOV, Valentin. Marxismo e filosofia da linguagem. 12. ed. São Paulo: Hucitec, 2006.

BUBNOVA, Tatiana. El marxismo y la Filosofía del Lenguaje: los principales problemas del método sociológico en la ciencia del lenguaje. Buenos Aires: Ediciones Godot, 2009.

MARCONDES, Danilo. A pragmática na filosofia contemporânea. Rio de Janeiro: Zahar, 2005.

MARX, Karl. ENGELS, Friedrich. A ideologia alemã. Trad. Luis Claudio de Castro e Costa. São Paulo: Martins Fontes, 2001.

A ideologia alemã. Trad. M. Backes. Rio de Janeiro: Civilização Brasileira, 2007. Contribuição à crítica da economia política. São Paulo: Martins Fontes, 1983.

. Teses sobre Feuerbach. Tradução autorizada de Álvaro Pina. 2003. Disponível em:

<https://www.marxists.org/portugues/marx/1845/tesfeuer.htm> Acesso em: 12 Dez. 2019.

VIANNA, Rodolfo. Marxismo e filosofia da linguagem à luz da ideologia alemã. Bakhtiniana, São Paulo, v. 1, n. 3, pp. 29-41. 2010.

\begin{tabular}{|l|l|l|l|l|}
\hline Q Ponista Dialectus & Ano 9 & n. 19 & Agosto-Dezembro 2020 & p. 278-288
\end{tabular}

